Supplement of Biogeosciences, 13, 5527-5539, 2016

http://www.biogeosciences.net/13/5527/2016/

doi:10.5194/bg-13-5527-2016-supplement

(C) Author(s) 2016. CC Attribution 3.0 License.

(c) (i)

Supplement of

\title{
Seasonal changes in the $D$ / $H$ ratio of fatty acids of pelagic microorganisms in the coastal North Sea
}

Sandra Mariam Heinzelmann et al.

Correspondence to: Sandra Mariam Heinzelmann (sandra.m.heinzelmann@gmail.com)

The copyright of individual parts of the supplement might differ from the CC-BY 3.0 licence. 
Figure legends Supplementary

\section{Figure S1}

Phylogenetic tree of $16 \mathrm{~S}$ rRNA gene sequence reads assigned to Bacteroidetes. Scale bar indicates $0.10 \%$ estimated sequence divergence. Groups containing sequences are highlighted.

\section{Figure S2}

Phylogenetic tree of $16 \mathrm{~S}$ rRNA gene sequence reads assigned to Alphaproteobacteria. Scale bar indicates $0.10 \%$ estimated sequence divergence. Groups containing sequences are highlighted.

\section{Figure S3}

Phylogenetic tree of $16 \mathrm{~S}$ rRNA gene sequence reads assigned to Gammaproteobacteria. Scale bar indicates $0.10 \%$ estimated sequence divergence. Groups containing sequences are highlighted.

\section{Figure S4}

$\delta D_{\text {water }}$ versus salinity of North Sea SPM sampled in 2013. 

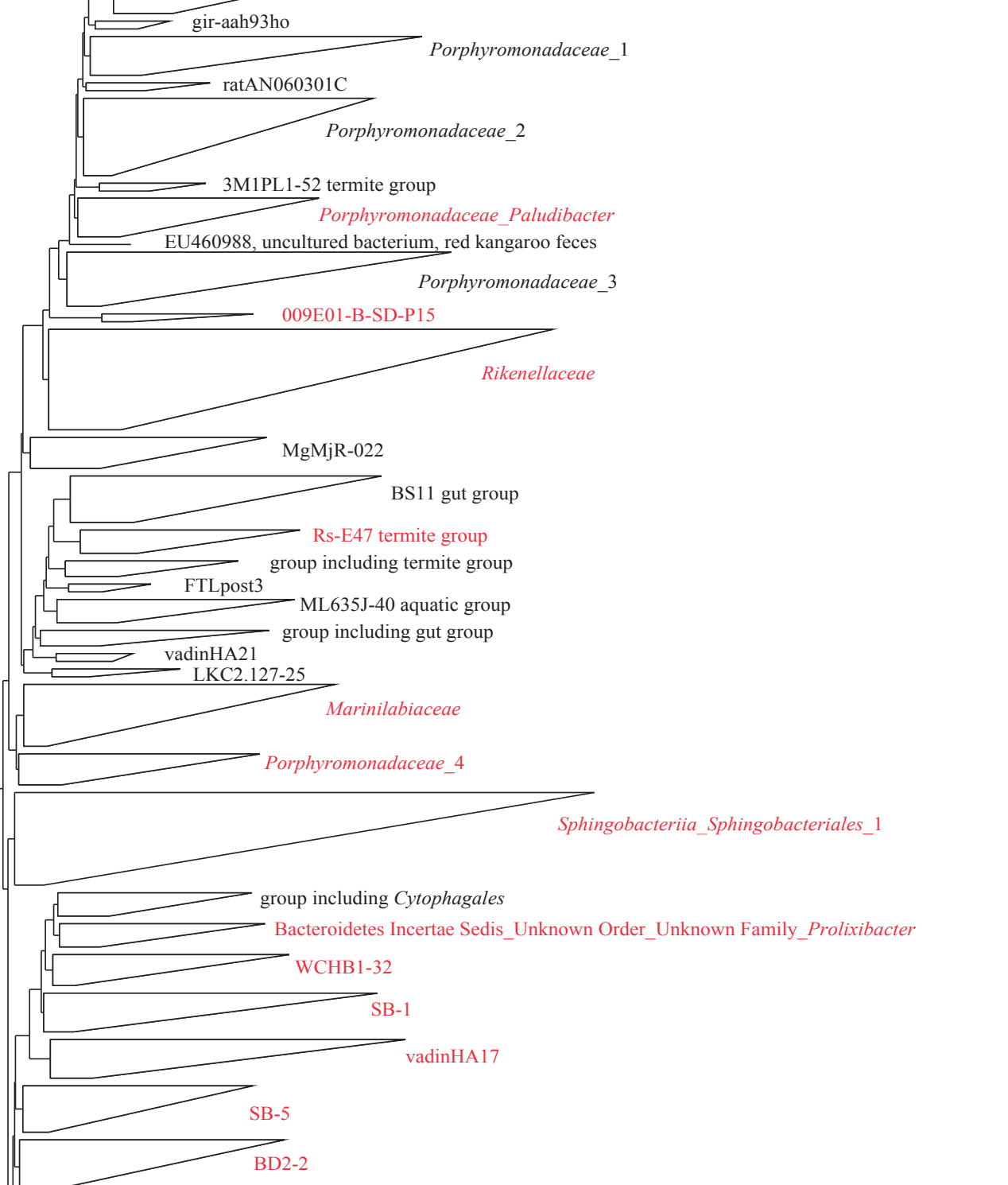

Ika-33
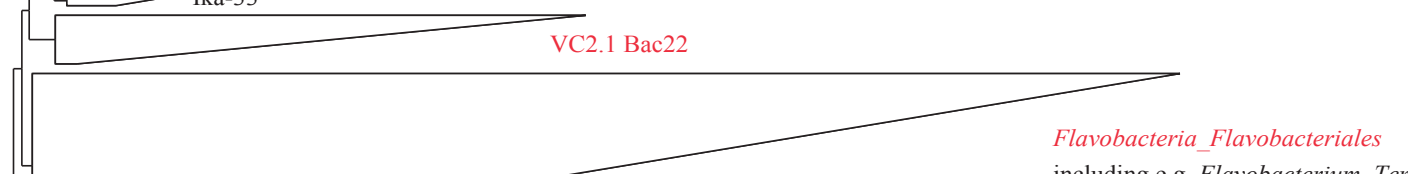

including e.g. Flavobacterium, Tenacibaculum,

Sufflavibacter, Fluviicola

\section{ML602M-17}

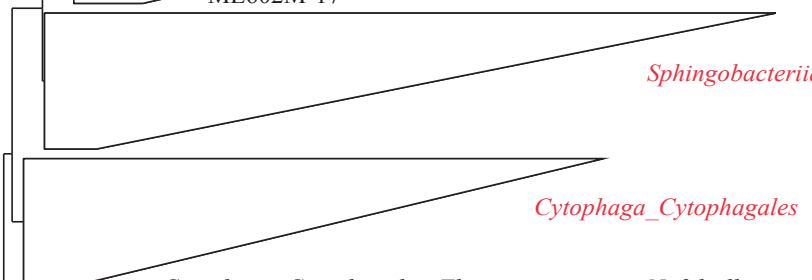

Cytophaga_Cytophagales Flammeovirgaceae Nafulsella Cytophaga Cytophagales FTammeovirgaceae Cesiribacter

SBXY-678 $\overline{6}$
Sytophaga_Cytophagales_Cytophagaceae_Flexibacter_1
Cytophaga_Order IV Unknown Family_Thermonema

Cytophaga Cytophagales Cytophagaceae Flexibacter

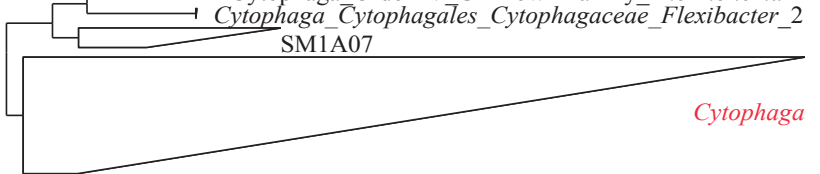




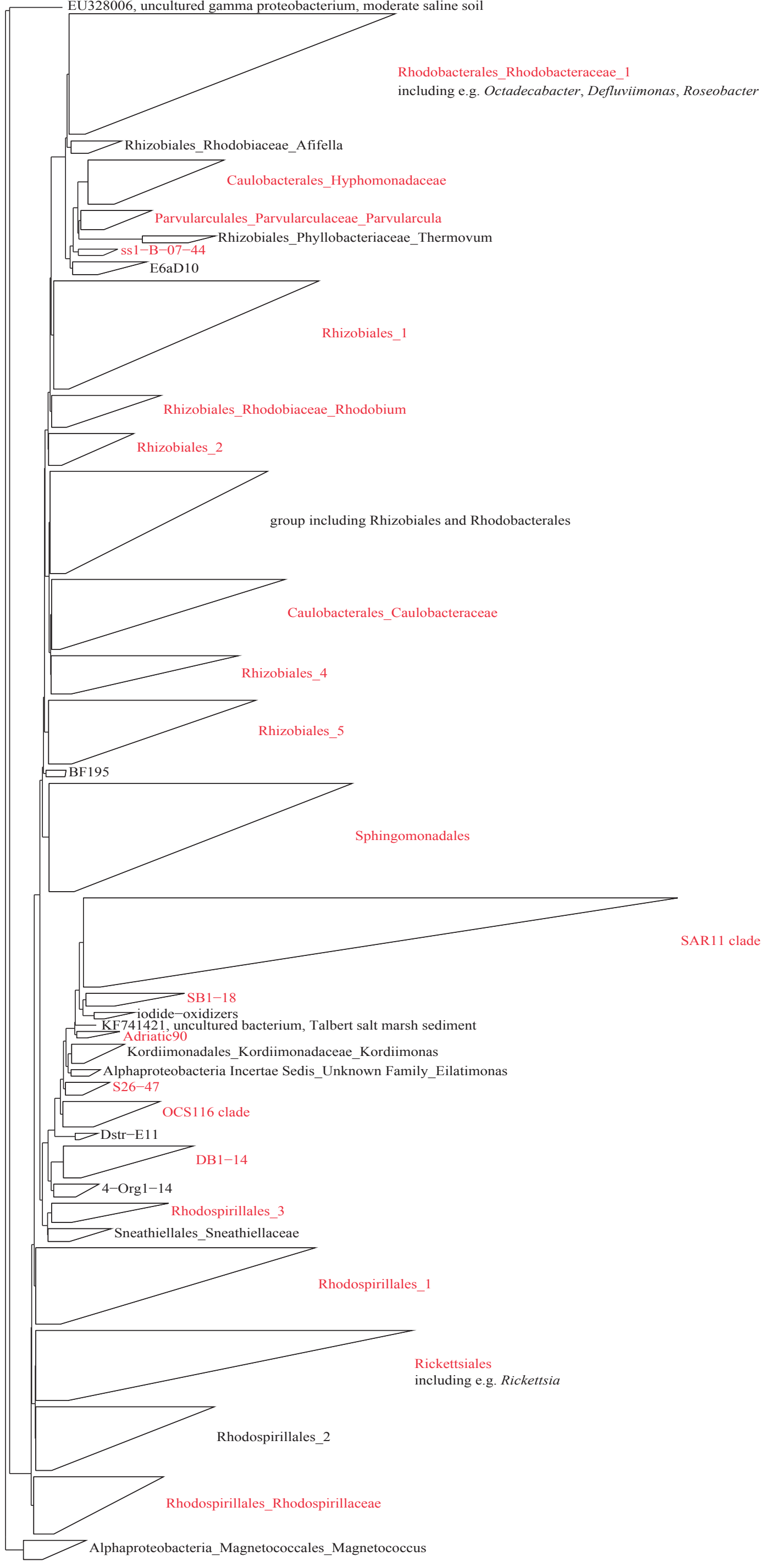

Rhodobacterales Rhodobacteraceae

cluding e.g. Octadecabacter, Defluviimonas, Roseobacter

$-\mathrm{B}-07-44$

$\longrightarrow$ Dstr-E11

$\longrightarrow$ DB1-14

4-Org1-14

Rnodospirillales_3

Rhodospirillales_

Rickettsiales

including e.g. Rickettsia 
Enterobacteriales_Enterobacteriaceae_1

group including Pasteurellales_Pasteurellaceae

FJ849406, uncultured bacterium, arctic stream sediment; non-carbonate lithology; site ID SNC03

$\nabla$ Enterobacteriales_Enterobacteriaceae_Serratia

- AM179917, uncultured bacterium, rainbow trout intestine

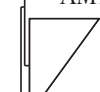
Enterobacteriales_Enterobacteriaceae_Plesiomonas

$\square \mathrm{PB} 1-\mathrm{aai} 25 \mathrm{f} 07$

GQ360009, uncultured bacterium, intestine content

HM779006, uncultured bacterium, intestines

HM778562, uncultured bacterium, intestines

HM778230, uncultured bacterium, intestines

nJFR0501-aaa03c07

HM778573, uncultured bacterium, intestines

HJFR0502-aaa15a10

HM778696, uncultured bacterium, intestines

HM779079, uncultured bacterium, intestines

- HM778342, uncultured bacterium, intestines

HM778237, uncultured bacterium, intestines

aаa34a 10

KF650752, Gallaecimonas sp. MA-8, intertidal sediment

KF835793, Aeromonas hydrophila, marine

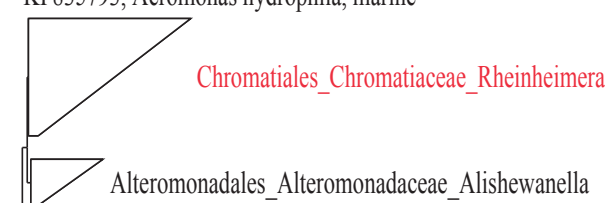

$\checkmark$ Gammaproteobacteria Incertae Sedis_Unknown Family_Alkalimonas

$\longrightarrow$ BM1-4-101

$\leftarrow$ EU560805, uncultured bacterium, intestinal flora

$\checkmark$ Alteromonadales_Moritellaceae_Paramoritella

$\checkmark$ Gammaproteobacteria Incertae Sedis_Unknown Family_Gallaecimonas

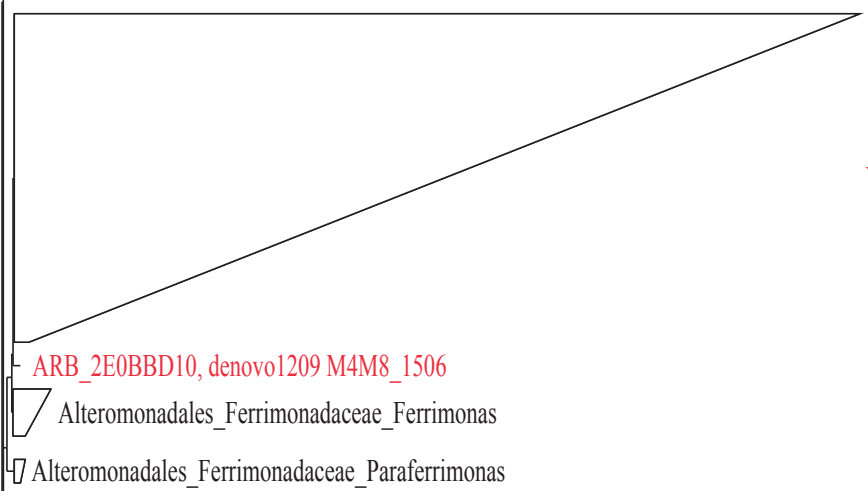

Vibrionales Vibrionaceae

47 Alteromonadales Ferrimonadaceae Paraferrimonas

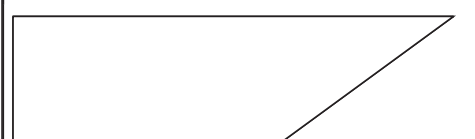




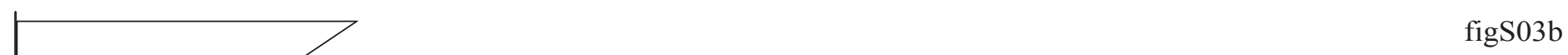

Aeromonadales

Alteromonadales_2

including Shewanella, Moritella

Oceanospirillales 1

including Halomonadaceae

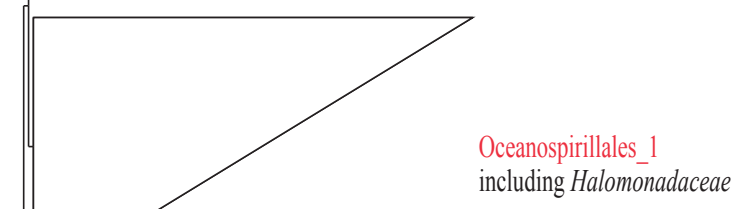

Oceanospirillales_Oceanospirillaceae_1
including Marinobacterium, Marinomonas

Oceanospirillales_Oceanospirillaceae_2

including Oceanobacter, Litoribacillus

Oceanospirillales_2
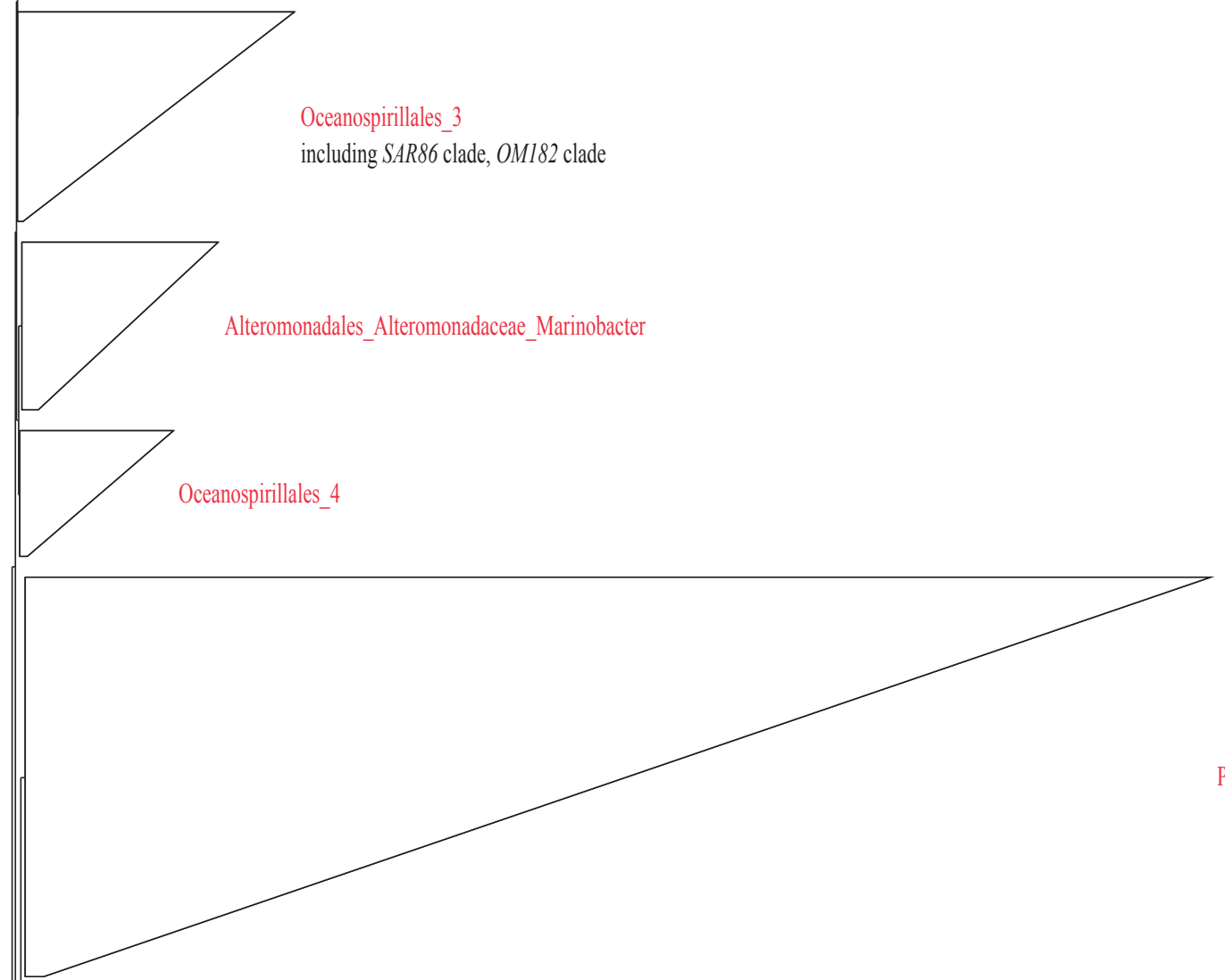

Pseudomonadales_Moraxellaceae

Alteromonadales_Alteromonadaceae including $0 M 60$ clade

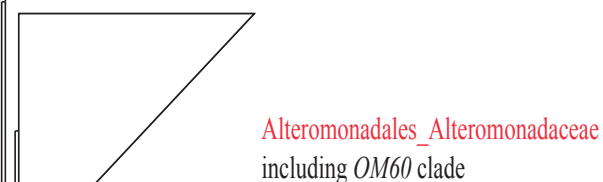

Pseudomonadales_Pseudomonadaceae_Cellvibrio

Oceanospirillales_Hahellaceae_Hahella

ARB 94C75DF7, denovo1692 M5M8_2552 


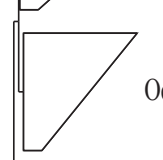

Oceanospirillales_Alcanivoracaceae_Alcanivora

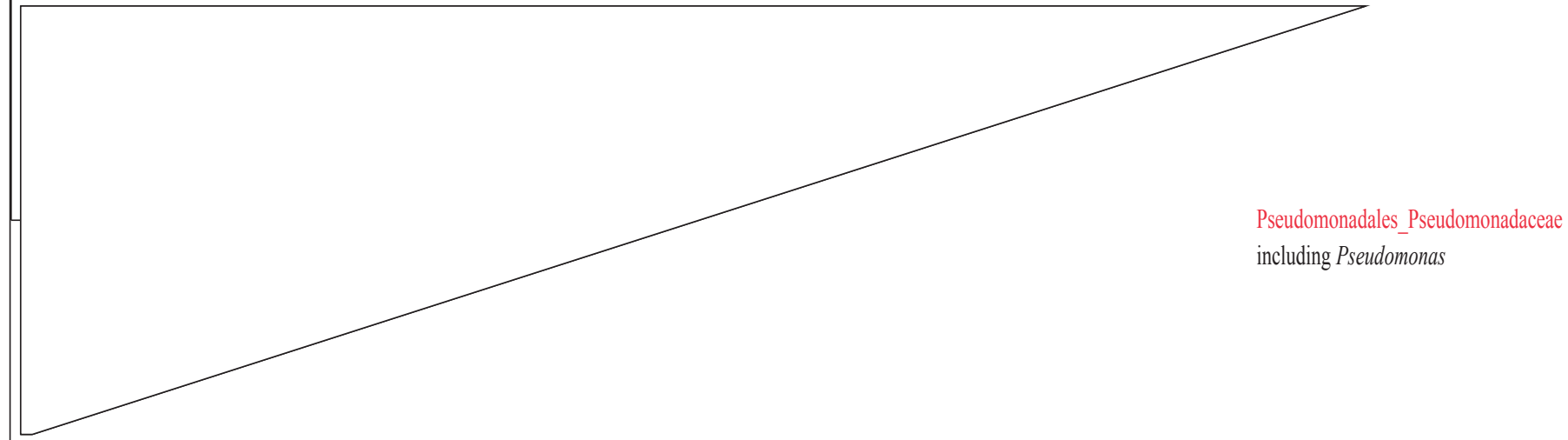

$\square$ BD3-1

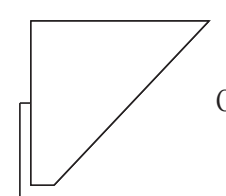

Gammaproteobacteria_Cardiobacteriales_Cardiobacteriaceae

Gammaproteobacteria_Xanthomonadales_Xanthomonadaceae

Gammaproteobacteria_Chromatiales_Halothiobacillaceae

\section{$\square$ MACA-EFT26}

$\int$ Proteobacteria Incertae Sedis_Unknown Order_Unkown Family_Candidatus Allobeggiatoa

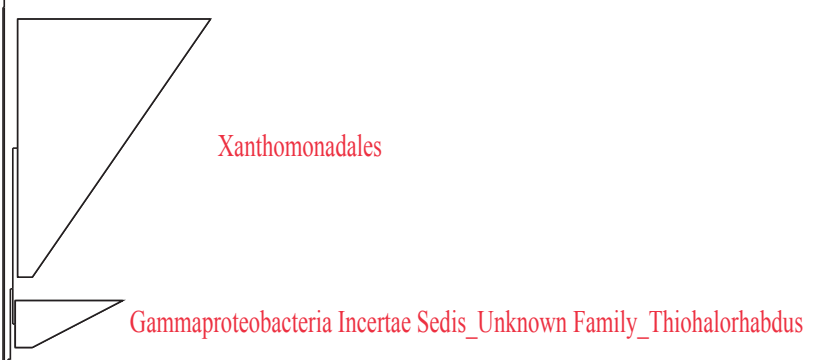

Chromatiales_Chromatiaceae_Nitrosococcus

Chromatiales Ectothiorhodospiraceae 1

Chromatiales_Ectothiorhodospiraceae_Acidiferrobacter

Acidithiobacillales

Thiotrichales_Thiotrichaceae

1013-28-CG33 


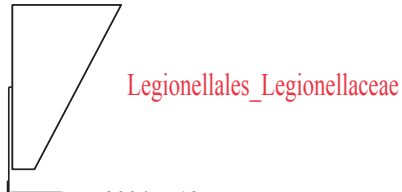

MD2904-B13

- ARB_18371AAB, denovo1227 M3M8 1547

$>\mathrm{EC} 3$

BD72BR169

J0347337, uncultured bacterium, Da Ya Bay

KC 492847, uncultured gamma proteobacterium, Baltic Sea redoxcline, $119 \mathrm{~m}$ depth

NKB5

Thiotrichales

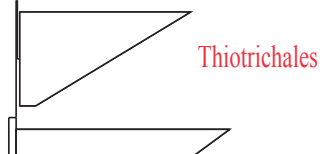

Legionellales_Coxiellaceae

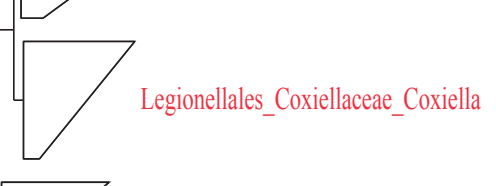

Methylococcales_Methylococcaceae_1

Chromatiales_Ectothiorhodospiraceae_2

$\square$ Methylococcales_Methylococcaceae_2

$\square$ Thiotrichales_Piscirickettsiaceae_Sulfurivirga

$\mathrm{WN}-\mathrm{HWB}-116$

$\square$ Gammaproteobacteria Incertae Sedis_Unknown Family_Methylonatrum

$\checkmark$ Chromatiales_Ectothiorhodospiraceae_Natronocella

HOC36

$\square$ DSM 5130

Chromatiales_Ectothiorhodospiraceae_3

C Salinisphaerales_Salinisphaeraceae

E01-9C-26 marine group

$\int$ Chromatiales_Ectothiorhodospiraceae_Thioalkalispira

Gammaproteobacteria Incertae Sedis_Unknown Family_Thiohalomonas

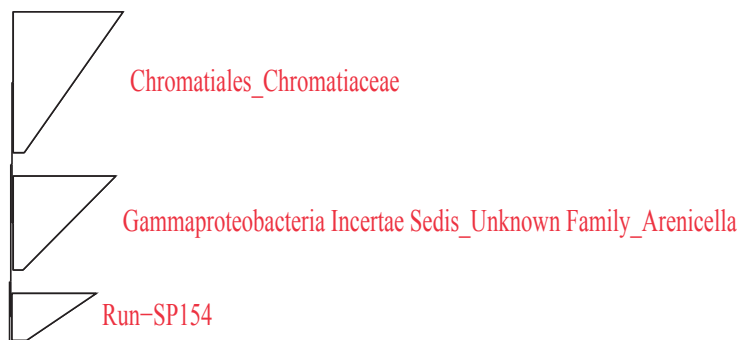

JF428849, uncultured bacterium, zero water exchange shrimp pond sediment AM176841, uncultured bacterium, mangrove sediment

$\square$ SZB30

L JX134740, uncultured gamma proteobacterium, fresh water sediment from Xi' an city moat GQ203633, uncultured proteobacterium, anaerobic sludge in ABR reactor

KI89A clade

$34 \mathrm{P} 16$

- 195up

- Thiotrichales_Thiotrichaceae_Achromatium

- AY344377, uncultured bacterium, Lake Kauhako $4 \mathrm{~m}$

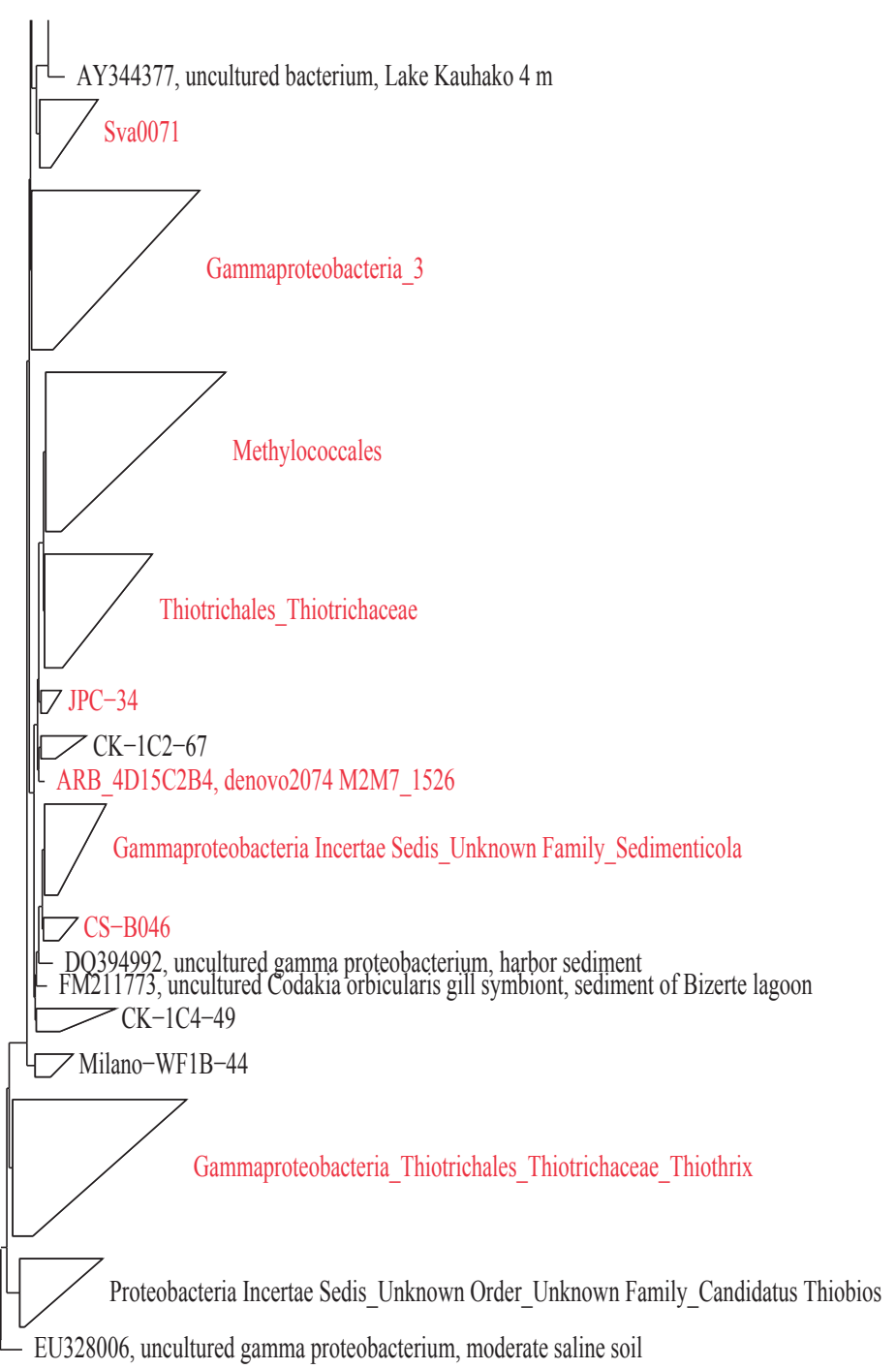




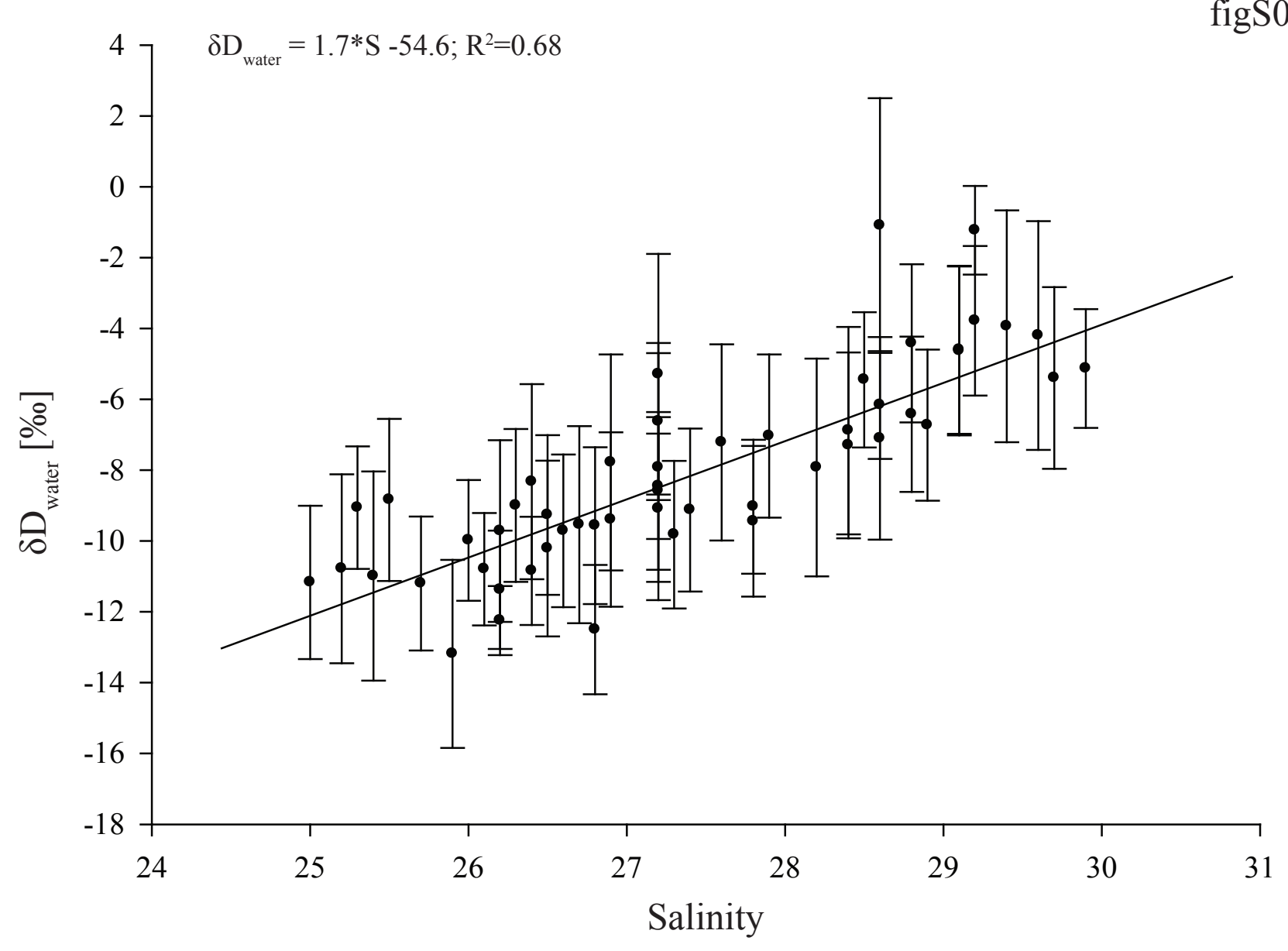




\section{Supplementary Data: Tables}

Table S1: Chlorophyll $a$ concentration measured between the $16 / 08 / 10$ and the $15 / 12 / 11$ in $\mu \mathrm{g} / \mathrm{L}$.

\begin{tabular}{llll}
\hline Date & c Chlorophyll $a[\mu \mathrm{g} / \mathrm{L}]$ & Date & c Chlorophyll $a$ [ $\mu \mathrm{g} / \mathrm{L}]$ \\
\hline $16 / 08 / 10$ & 7.1 & $06 / 06 / 11$ & 5.1 \\
$30 / 08 / 10$ & 6.7 & $09 / 06 / 11$ & 4.4 \\
$15 / 09 / 10$ & 7.7 & $17 / 06 / 11$ & 2.9 \\
$28 / 09 / 10$ & 4.6 & $23 / 06 / 11$ & 4.5 \\
$22 / 10 / 10$ & 4.0 & $30 / 06 / 11$ & 6.3 \\
$01 / 11 / 10$ & 4.1 & $04 / 07 / 11$ & 6.7 \\
$15 / 11 / 10$ & 1.9 & $15 / 07 / 11$ & 5.7 \\
$26 / 11 / 10$ & 3.6 & $21 / 07 / 11$ & 3.3 \\
$17 / 12 / 10$ & 4.5 & $27 / 07 / 11$ & 5.7 \\
$24 / 01 / 11$ & 3.7 & $01 / 08 / 11$ & 3.2 \\
$10 / 02 / 11$ & 1.2 & $08 / 08 / 11$ & 5.6 \\
$23 / 02 / 11$ & 0.5 & $22 / 08 / 11$ & 6.6 \\
$08 / 03 / 11$ & 5.2 & $29 / 08 / 11$ & 4.4 \\
$23 / 03 / 11$ & 12.9 & $12 / 09 / 11$ & 4.6 \\
$05 / 04 / 11$ & 22.2 & $21 / 09 / 11$ & 1.8 \\
$11 / 04 / 11$ & 8.6 & $29 / 09 / 11$ & 3.4 \\
$19 / 04 / 11$ & 10.7 & $14 / 10 / 11$ & 1.8 \\
$26 / 04 / 11$ & 14.0 & $20 / 10 / 11$ & 3.0 \\
$03 / 05 / 11$ & 5.0 & $31 / 10 / 11$ & 2.7 \\
$11 / 05 / 11$ & 5.5 & $15 / 11 / 11$ & 2.6 \\
$18 / 05 / 11$ & 2.0 & $28 / 11 / 11$ & 2.0 \\
$24 / 05 / 11$ & 10.8 & $15 / 12 / 11$ & 1.6 \\
$01 / 06 / 11$ & 1.8 & & \\
\hline & & &
\end{tabular}


Table S2: Phytoplankton diversity and abundance. Abundance measured in cells/L. 


\begin{tabular}{|c|c|c|c|c|c|c|c|c|c|c|c|c|c|c|c|c|}
\hline \multirow[t]{3}{*}{ Dates } & \multicolumn{16}{|c|}{ cells/L $\left[\mathrm{x} 10^{6}\right]$} \\
\hline & \multicolumn{5}{|c|}{ cyanobacteria } & \multicolumn{2}{|c|}{ Cryptophyta } & \multicolumn{2}{|c|}{ Chlorophyta } & \multicolumn{5}{|c|}{ Diatoms } & \multirow{2}{*}{$\frac{\text { Haptophyta }}{\mathrm{O}}$} & \multirow[b]{2}{*}{ Total } \\
\hline & $\mathrm{A}$ & $\mathrm{B}$ & $\mathrm{C}$ & $\mathrm{D}$ & $\mathrm{E}$ & $\mathrm{F}$ & $\mathrm{G}$ & $\mathrm{H}$ & $\mathrm{I}$ & $\mathrm{J}$ & $\mathrm{H}$ & & $\mathrm{M}$ & $\mathrm{N}$ & & \\
\hline $08 / 09 / 10$ & 6 & 3 & & & & & & & & & & & & & & 9 \\
\hline $15 / 09 / 10$ & & & 3 & & & & & & & & & & & & & 3 \\
\hline $23 / 09 / 10$ & & & & & & 2 & & & & & & & & & & 2 \\
\hline $28 / 09 / 10$ & & 1 & & & & & & 1 & & & & & & & & 2 \\
\hline $08 / 10 / 10$ & & & & & & & & 1 & & & & & & & & 1 \\
\hline $14 / 10 / 10$ & & & 42 & & & & & & & & & & & & & 42 \\
\hline $22 / 10 / 10$ & & & & & & & & 1 & & 2 & & & & & & 3 \\
\hline $01 / 11 / 10$ & & 1 & & & & & & & & & & & & & & 1 \\
\hline $15 / 11 / 10$ & & & & & & & & 2 & & & & & & & & 2 \\
\hline $26 / 11 / 10$ & & & & & & & & 2 & 2 & & & & & & & 4 \\
\hline $17 / 12 / 10$ & & & 9 & & & & & & 2 & & & & & & & 11 \\
\hline $24 / 01 / 11$ & & & 3 & 13 & & & & & 2 & & & & & & & 18 \\
\hline $10 / 02 / 11$ & & & & & & & & 2 & & & & & & & & 2 \\
\hline $23 / 02 / 11$ & & & 1 & & & & & & & & & & & & & 1 \\
\hline $08 / 03 / 11$ & & & & & & & & & & 2 & & & & & & 2 \\
\hline $15 / 03 / 11$ & & & & & & & & & & 2 & & & & & & 2 \\
\hline $23 / 03 / 11$ & & & & & & & & 1 & & & 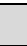 & & & & & 2 \\
\hline $28 / 03 / 11$ & & & & & & & & & & 2 & 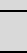 & & & & & 3 \\
\hline $05 / 04 / 11$ & & & & & & & & & & & 3 & & & & & 3 \\
\hline $11 / 04 / 11$ & & & & & & 0.5 & & & & & & & & & & 0.5 \\
\hline 19/04/11 & & & & & & 1 & & & & 2 & & & & & 7 & 10 \\
\hline $26 / 04 / 11$ & & & & & & & & & & & & & & & 21 & 30 \\
\hline $03 / 05 / 11$ & & & & & & & & & & & & & & & 26 & 29 \\
\hline $11 / 05 / 11$ & & & & & & & & & & & & & 2 & & 13 & 15 \\
\hline $18 / 05 / 11$ & & & & & & & & & & & & & & 0.5 & & 0.5 \\
\hline $24 / 05 / 11$ & & & & & & & & & & 2 & & & & & & 5 \\
\hline $06 / 06 / 11$ & & & & & & & & 1 & & 1 & & & & & & 2 \\
\hline $09 / 06 / 11$ & & & & & & & 0.5 & 1 & & & & & & & & 1.5 \\
\hline $17 / 06 / 11$ & & & & & & & & & & & & & & & 1 & 1 \\
\hline $23 / 06 / 11$ & & & & & & & & & & & & & & & 1 & 1 \\
\hline $30 / 06 / 11$ & & & & & & & & & & & & & & & 3 & 3 \\
\hline $04 / 07 / 11$ & & 0.5 & & & & & & & & & & & & & & 0.5 \\
\hline $15 / 07 / 11$ & & 1 & & & & & & & & & & & & & & 1 \\
\hline $21 / 07 / 11$ & & & & & & & & & & & & & & & & 1 \\
\hline $27 / 07 / 11$ & 6 & & & & & & & & & & & & & & & 6 \\
\hline $01 / 08 / 11$ & 9 & & & & & & & & & 2 & & & & & & 11 \\
\hline $08 / 08 / 11$ & & & & & & & & & & 1 & & & & & 1 & 2 \\
\hline $15 / 08 / 11$ & & & & & & & & & & & & & & & 1 & 1 \\
\hline $22 / 08 / 11$ & & & & & & & & & & & & & & & 2 & 2 \\
\hline $29 / 08 / 11$ & & & & & & 0.5 & & & & & & & & & & 0.5 \\
\hline $12 / 09 / 11$ & & & & & 1 & & & & & & & & & & & 1 \\
\hline $15 / 09 / 11$ & 8 & & & & & & & & & & & & & & & 8.2 \\
\hline $21 / 09 / 11$ & & & & & & & 0.2 & & & & & & & & & 2 \\
\hline $29 / 09 / 11$ & & & & & & 1 & & & & 1 & & & & & & 2 \\
\hline $14 / 10 / 11$ & & & & & & 1 & & 1 & & & & & & & & 2 \\
\hline $20 / 10 / 11$ & & & & & & & & & & & & & & & 2 & 2 \\
\hline $31 / 10 / 11$ & & & & & & & & 1 & & & & & & & & 1 \\
\hline $15 / 11 / 11$ & & 3 & & & & & & & & & & & & & & 3 \\
\hline $28 / 11 / 11$ & & & & & & & & 2 & & & & & & & & 2 \\
\hline $15 / 12 / 11$ & & & & & & & & 2 & & 1 & & & & & & 3 \\
\hline
\end{tabular}

Cyanobacteria: A Chroococcaceae, B Chlorococcales, C Cyanophyta, D Snowella, E Microcystis; Cryptohyta: F Hemiselmis, G Plagioselmis; Chlorophyta: H Prasinophyceae, I Chlorophyta; Diatoms: J Bacillariales, K Thalassiosiraceae, L Chaetoceros, M Pseudo-nitzschia delicatissima, N Cylindrotheca closterium; Haptophyta: O Phaeocystis globosa 
Table S3a: Phyla-level bacterial diversity and abundance in North Sea SPM based on the 16S rRNA gene amplicon sequencing. Diversity and abundance of Proteobacteria on class level. Percentage based on total bacteria reads including Chloroplast reads.

\begin{tabular}{|c|c|c|c|c|c|c|c|c|c|c|c|c|c|c|c|c|}
\hline \multirow[t]{2}{*}{ bacterial groups } & \multicolumn{4}{|c|}{$\%$ of total bacteria reads } & \multirow[b]{2}{*}{$23 / 03$} & \multirow[b]{2}{*}{$05 / 04$} & \multirow[b]{2}{*}{$19 / 04$} & \multirow[b]{2}{*}{$03 / 05$} & \multirow[b]{2}{*}{$18 / 05$} & \multirow[b]{2}{*}{$17 / 06$} & \multirow[b]{2}{*}{$30 / 06$} & \multirow[b]{2}{*}{$15 / 07$} & \multirow[b]{2}{*}{$22 / 08$} & \multirow[b]{2}{*}{$06 / 09$} & \multirow[b]{2}{*}{$21 / 09$} & \multirow[b]{2}{*}{$\begin{array}{l}28 / 10 / 2 \\
011\end{array}$} \\
\hline & $\begin{array}{l}28 / 09 / 2 \\
010\end{array}$ & $26 / 11$ & $\begin{array}{l}10 / 01 / 2 \\
011 \\
\end{array}$ & $08 / 03$ & & & & & & & & & & & & \\
\hline Actinobacteria & 5.2 & 6.7 & 3.9 & 1.5 & 1.0 & 0.8 & 1.2 & 1.4 & 7.3 & 5.7 & 4.7 & 3.3 & 9.5 & 5.5 & 10.6 & 7.4 \\
\hline Bacteriodetes & 20.8 & 16.7 & 16.9 & 15.3 & 18.8 & 29.8 & 33.8 & 31.8 & 35.5 & 29.3 & 32.3 & 26.7 & 23.1 & 22.9 & 17.8 & 17.3 \\
\hline Cyanobacteria & 6.7 & 10.0 & 13.2 & 41.9 & 21.5 & 17.4 & 5.8 & 15.2 & 1.2 & 10.9 & 6.9 & 10.5 & 14.5 & 9.7 & 8.3 & 10.0 \\
\hline Planctomycetes & 9.6 & 4.0 & 3.7 & 3.0 & 2.6 & 1.1 & 0.2 & 0.7 & 0.5 & 1.1 & 0.6 & 1.6 & 2.3 & 3.0 & 4.3 & 3.5 \\
\hline$\alpha$-Proteobacteria & 21.9 & 30.0 & 24.5 & 18.5 & 20.4 & 25.2 & 26.1 & 17.1 & 21.1 & 17.1 & 18.2 & 18.5 & 22.8 & 20.2 & 25.0 & 22.6 \\
\hline$\beta$-Proteobacteria & 2.0 & 4.5 & 10.2 & 8.1 & 5.1 & 3.1 & 5.3 & 3.6 & 3.8 & 1.9 & 3.3 & 4.1 & 3.6 & 2.4 & 3.1 & 5.8 \\
\hline$\delta$-Proteobacteria & 3.0 & 4.3 & 3.7 & 4.9 & 3.8 & 1.4 & 0.8 & 2.5 & 1.8 & 4.9 & 1.3 & 4.0 & 2.7 & 5.4 & 5.6 & 5.7 \\
\hline$\gamma$-Proteobacteria & 23.6 & 22.7 & 25.6 & 23.1 & 27.3 & 19.8 & 25.7 & 32.5 & 23.8 & 30.0 & 27.0 & 27.3 & 22.2 & 28.2 & 23.9 & 27.5 \\
\hline Verrucomicrobia & 6.4 & 3.7 & 2.3 & 3.6 & 8.2 & 9.0 & 4.0 & 2.7 & 4.5 & 3.6 & 8.0 & 6.3 & 6.0 & 3.8 & 2.1 & 2.2 \\
\hline
\end{tabular}


Table S3b: Order-level bacterial diversity and abundance in North Sea SPM based on the 16S rRNA gene amplicon sequencing. Percentage based on total bacteria reads excluding Chloroplast reads.

\begin{tabular}{|c|c|c|c|c|c|c|c|c|c|c|c|c|c|c|c|c|}
\hline \multirow[t]{2}{*}{ bacterial groups } & \multicolumn{16}{|c|}{$\%$ of total bacteria reads } \\
\hline & $\begin{array}{l}28 / 09 / \\
2010\end{array}$ & $26 / 11$ & $\begin{array}{l}10 / 01 / \\
2011\end{array}$ & $08 / 03$ & $23 / 03$ & $05 / 04$ & $19 / 04$ & $03 / 05$ & $18 / 05$ & $17 / 06$ & $30 / 06$ & $15 / 07$ & $22 / 08$ & $06 / 09$ & $21 / 09$ & $\begin{array}{l}28 / 10 / \\
2011\end{array}$ \\
\hline Acidimicrobiales & 1.7 & 3.4 & 1.1 & 1.1 & 0.8 & 0.2 & 0.3 & 0.5 & 1.2 & 3.3 & 2.4 & 1.4 & 4.7 & 4.6 & 10.8 & 6.7 \\
\hline Micrococcales & 3.2 & 1.7 & 1.1 & 0.2 & 0.1 & 0.6 & 0.8 & 1.1 & 6.1 & 2.6 & 2.4 & 2.0 & 5.8 & 1.2 & 0.3 & 0.2 \\
\hline Flavobacteriales & 16.2 & 13.2 & 10.6 & 16.8 & 14.7 & 27.9 & 29.7 & 30.8 & 28.6 & 25.3 & 27.8 & 22.1 & 21.0 & 17.3 & 14.2 & 13.4 \\
\hline Sphingobacteriales & 3.4 & 2.7 & 4.6 & 4.6 & 4.5 & 3.9 & 3.6 & 3.3 & 3.2 & 4.1 & 3.8 & 3.1 & 3.5 & 2.7 & 2.7 & 2.9 \\
\hline Pirellulales & 8.1 & 2.9 & 2.9 & 3.1 & 2.6 & 0.6 & 0.1 & 0.3 & 0.1 & 0.3 & 0.4 & 1.0 & 1.8 & 2.1 & 3.4 & 2.7 \\
\hline Rhodobacterales & 8.2 & 12.4 & 9.7 & 9.2 & 8.4 & 5.6 & 6.5 & 5.9 & 9.1 & 11.2 & 9.1 & 5.8 & 9.1 & 10.0 & 11.6 & 6.4 \\
\hline Rickettsiales & 8.4 & 12.2 & 12.0 & 6.1 & 8.7 & 16.8 & 15.5 & 7.0 & 5.5 & 2.6 & 3.2 & 6.0 & 7.6 & 5.6 & 7.5 & 9.9 \\
\hline Methylophiales & 0.9 & 1.8 & 2.5 & 1.9 & 1.0 & 1.0 & 1.2 & 0.7 & 1.7 & 1.0 & 2.3 & 2.4 & 2.0 & 1.7 & 1.6 & 4.0 \\
\hline Rhodocyclales & 0.9 & 2.1 & 6.5 & 5.1 & 3.7 & 2.1 & 3.9 & 2.5 & 1.3 & 0.4 & 0.7 & 1.4 & 1.1 & 0.5 & 0.1 & 0.9 \\
\hline Alteromonadales & 10.7 & 9.3 & 13.2 & 11.8 & 12.7 & 8.8 & 11.6 & 17.0 & 9.7 & 17.3 & 13.1 & 14.1 & 10.0 & 12.0 & 8.9 & 11.1 \\
\hline Oceanospirillales & 3.0 & 7.9 & 4.3 & 5.1 & 7.3 & 7.4 & 12.0 & 7.8 & 10.5 & 7.1 & 8.1 & 6.5 & 6.6 & 7.2 & 8.7 & 8.4 \\
\hline Thiotrichales & 3.1 & 1.6 & 2.9 & 1.6 & 2.4 & 1.2 & 0.4 & 3.8 & 1.6 & 1.7 & 3.2 & 2.6 & 3.1 & 3.4 & 1.4 & 2.5 \\
\hline Puniceicoccales & 0.6 & 1.0 & 0.3 & 1.9 & 5.4 & 8.5 & 3.4 & 1.3 & 0.9 & 0.4 & 5.6 & 2.6 & 3.5 & 1.4 & 0.9 & 0.7 \\
\hline Verrucomicrobiales & 5.1 & 1.0 & 1.1 & 2.9 & 4.5 & 2.3 & 0.7 & 1.7 & 2.3 & 3.2 & 2.8 & 3.7 & 3.3 & 1.3 & 0.8 & 1.0 \\
\hline
\end{tabular}

Actinobacteria: Acidimicrobiales, Micrococcales; Bacteroidetes: Flavobacteriales, Sphingobacteriales; Planctomycetes: Pirellulales; $\alpha-P r o t e o b a c t e r i a: ~ R h o d o b a c t e r a l e s$, Rickettsiales; $\beta$-Proteobacteria: Methylophiales, Rhodocyclales; $\gamma$-Proteobacteria: Alteromonadales, Oceanospirillales, Thiotrichales; Verrucomicrobia: Puniceicoccales,

Verrucomicrobiales 
Table S4: Fatty acid abundance in North Sea water samples.

\begin{tabular}{lllllll}
\hline Date & \multicolumn{7}{l}{ Fatty acid abundance [\%] } & & & \\
\cline { 2 - 7 } & C14:0 & C16:1* & C16:0 & C18:x & C18:0 & C20:5 PUFA \\
\hline $16 / 08 / 10$ & 14 & 23 & 36 & 16 & 6 & 5 \\
$30 / 08 / 10$ & 17 & 26 & 29 & 15 & 6 & 7 \\
$15 / 09 / 10$ & 19 & 27 & 32 & 14 & 5 & 4 \\
$28 / 09 / 10$ & 14 & 24 & 29 & 18 & 9 & 7 \\
$15 / 11 / 10$ & 13 & 17 & 32 & 23 & 13 & 3 \\
$26 / 11 / 10$ & 13 & 20 & 31 & 21 & 13 & 2 \\
$10 / 12 / 10$ & 12 & 13 & 35 & 28 & 11 & 1 \\
$17 / 12 / 10$ & 11 & 30 & 28 & 26 & 4 & 0 \\
$10 / 01 / 11$ & 9 & 27 & 32 & 23 & 8 & 0 \\
$24 / 01 / 11$ & 7 & 23 & 29 & 30 & 7 & 4 \\
$17 / 02 / 11$ & 8 & 27 & 31 & 24 & 9 & 0 \\
$08 / 03 / 11$ & 11 & 35 & 24 & 16 & 3 & 11 \\
$23 / 03 / 11$ & 13 & 33 & 21 & 17 & 5 & 12 \\
$05 / 04 / 11$ & 10 & 34 & 26 & 13 & 4 & 13 \\
$19 / 04 / 11$ & 13 & 35 & 25 & 11 & 2 & 14 \\
$03 / 05 / 11$ & 17 & 23 & 23 & 22 & 2 & 12 \\
$18 / 05 / 11$ & 17 & 28 & 29 & 12 & 6 & 9 \\
$17 / 06 / 11$ & 21 & 21 & 35 & 9 & 10 & 4 \\
$30 / 06 / 11$ & 27 & 20 & 26 & 14 & 5 & 8 \\
$15 / 07 / 11$ & 21 & 25 & 28 & 9 & 7 & 10 \\
$27 / 07 / 11$ & 16 & 25 & 33 & 11 & 10 & 5 \\
$08 / 08 / 11$ & 14 & 25 & 26 & 10 & 7 & 18 \\
$22 / 08 / 11$ & 21 & 15 & 31 & 17 & 8 & 7 \\
$06 / 09 / 11$ & 14 & 20 & 32 & 10 & 18 & 6 \\
$21 / 09 / 11$ & 13 & 16 & 38 & 20 & 10 & 3 \\
$11 / 10 / 11$ & 16 & 22 & 37 & 13 & 11 & 0 \\
$28 / 10 / 11$ & 12 & 21 & 32 & 22 & 9 & 5 \\
$15 / 11 / 11$ & 12 & 25 & 31 & 17 & 8 & 6 \\
$28 / 11 / 11$ & 15 & 26 & 32 & 15 & 7 & 5 \\
$16 / 12 / 11$ & 8 & 27 & 30 & 19 & 9 & 6 \\
\hline
\end{tabular}

$n$ C16:1*: double bond at the $\omega 7$ position 
Table S5: $\delta \mathrm{D}$ values of fatty acids.

\begin{tabular}{|c|c|c|c|c|c|}
\hline \multirow[t]{2}{*}{ Date } & \multicolumn{5}{|c|}{$\delta D_{\text {fatty acid }}[\% o]$} \\
\hline & C14:0 & C16:0 & C16:1* & C18:0 & C20:5 PUFA \\
\hline $16 / 08 / 10$ & -219 & -201 & -201 & -185 & -191 \\
\hline $30 / 08 / 10$ & -222 & -202 & -189 & -186 & -199 \\
\hline $15 / 09 / 10$ & -216 & -206 & -197 & -186 & -180 \\
\hline 28/09/10 & -219 & -198 & -192 & -197 & -207 \\
\hline $15 / 11 / 10$ & -213 & -203 & -182 & -200 & N.D. \\
\hline $26 / 11 / 10$ & -226 & -202 & -188 & -203 & N.D. \\
\hline $10 / 12 / 10$ & -225 & -188 & -191 & -202 & N.D. \\
\hline $17 / 12 / 10$ & -232 & -193 & -194 & -188 & N.D. \\
\hline 10/01/11 & -221 & -200 & -186 & -204 & N.D. \\
\hline 24/01/11 & -212 & -191 & -195 & -192 & -209 \\
\hline $17 / 02 / 11$ & -223 & -208 & -195 & -206 & N.D. \\
\hline 08/03/11 & -226 & -214 & -205 & -182 & -235 \\
\hline 23/03/11 & -241 & -216 & -205 & -190 & -241 \\
\hline 05/04/11 & -223 & -210 & -209 & -212 & -223 \\
\hline 19/04/11 & -235 & -224 & -221 & N.D. & -240 \\
\hline 03/05/11 & -238 & -225 & -214 & -212 & -236 \\
\hline $18 / 05 / 11$ & -219 & -205 & -198 & -178 & -214 \\
\hline $17 / 06 / 11$ & -225 & -211 & -196 & -190 & N.D. \\
\hline $30 / 06 / 11$ & -225 & -210 & -202 & -175 & -213 \\
\hline $15 / 07 / 11$ & -204 & -195 & -188 & -181 & -217 \\
\hline $27 / 07 / 11$ & -220 & -200 & -203 & -180 & -201 \\
\hline 08/08/11 & -222 & -202 & -201 & -180 & -234 \\
\hline $22 / 08 / 11$ & -231 & -202 & -189 & -190 & -202 \\
\hline 06/09/11 & -224 & -217 & -221 & -216 & -218 \\
\hline 21/09/11 & -218 & -204 & -185 & -194 & N.D. \\
\hline $11 / 10 / 11$ & -213 & -191 & -183 & -188 & -226 \\
\hline 28/10/11 & -217 & -187 & -181 & -184 & -207 \\
\hline $15 / 11 / 11$ & -212 & -198 & -191 & -184 & -221 \\
\hline 28/11/11 & -217 & -193 & -190 & -180 & -197 \\
\hline $16 / 12 / 11$ & -198 & -179 & -174 & -188 & N.D. \\
\hline
\end{tabular}

$n$ C16:1*: double bond at the $\omega 7$ position 
Table S6: Fatty acid profiles of the bacterio- and phytoplankton observed via 16S rRNA gene amplicon sequencing and microscopy.

\begin{tabular}{|c|c|c|}
\hline Organism & Fatty acid profile & Literature \\
\hline Acidimicrobiales & $\begin{array}{l}\text { OCS155: uncultured } \\
\text { Microthrixaceae: fatty acid } \\
\text { profile not determined }\end{array}$ & \\
\hline Micrococcales & $\begin{array}{l}\text { Microbacteriaceae: mainly } \\
\text { ai } \mathrm{C} 15: 0, i \mathrm{C} 16: 0, a \mathrm{C} 17: 0\end{array}$ & $\begin{array}{ll}\text { (Evtushenko and } & \text { anchi, 2006) }\end{array}$ \\
\hline Flavobacteriales & $\begin{array}{l}\text { Flavobacteriaceae: mainly } \\
i \mathrm{C} 15: 0, \text { aiC } 15: 0, \mathrm{C} 15: 0 ; \text { only } \\
\text { traces of } \mathrm{C} 16: 0, \mathrm{C} 18: 0, \mathrm{C} 14: 0 \\
\begin{array}{l}\text { Cryomorphaceae: mainly } \\
i \mathrm{C} 15: 0, \quad i \mathrm{C} 15: 1 \omega 10, \mathrm{C} 15: 0 ; \\
\text { only traces of } \mathrm{C} 16: 0, \mathrm{C} 18: 0, \\
\mathrm{C} 14: 0\end{array}\end{array}$ & $\begin{array}{l}\text { (Van Trappen et al., } \\
\text { 2004b; Khan et al., } \\
\text { 2006; Heindl et al., } \\
\text { 2008) } \\
\text { (Bowman et al., 2003; } \\
\text { O'Sullivan et al., 2005) }\end{array}$ \\
\hline Sphingobacteriales & $\begin{array}{l}\text { Sphingobacteriaceae: mainly } \\
i \mathrm{C} 15: 0, \quad \mathrm{iC} 17: 0 \text { 3-OH, } \\
i \mathrm{C} 17: 1 \omega 9 \text { and potentially } \\
\mathrm{C} 16: 1 \omega 7 \text {; minor amounts of } \\
\mathrm{C} 16: 0 \text { and } \mathrm{C} 14: 0 \\
\mathrm{NS} 11-12 \text { : uncultured }\end{array}$ & (Gallego et al., 2006) \\
\hline Pirellulales & $\begin{array}{l}\text { Pirellulaceae: mainly C16:0, } \\
\mathrm{C} 18: 1 \omega 9 \text {; minor amounts of } \\
\mathrm{C} 14: 0, \mathrm{C} 16: 1 \omega 7 \text { and } \mathrm{C} 18: 0\end{array}$ & $\begin{array}{l}\text { (Kerger et al., 1988; } \\
\text { Schlesner et al., 2004) }\end{array}$ \\
\hline Rhodobacterales & 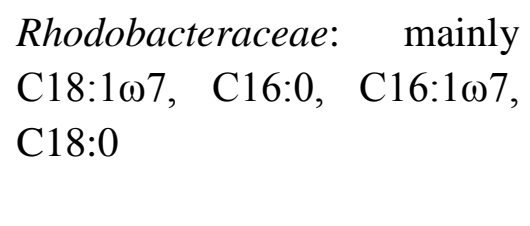 & $\begin{array}{l}\text { (Yoon et al., 2007a; } \\
\text { Venkata Ramana et al., } \\
\text { 2009; Jung et al., 2010; } \\
\text { Park and Yoon, 2014) }\end{array}$ \\
\hline Rickettsiales & $\begin{array}{l}\text { SAR11 cluster: fatty acid } \\
\text { profile not determined }\end{array}$ & \\
\hline Methylophiales & $\begin{array}{l}\text { Methylophilaceae: mainly } \\
\text { C16:0 and } \mathrm{C} 16: 1 \omega 7 \text {; traces of } \\
\text { C18:0 }\end{array}$ & $\begin{array}{l}\text { (Kalyuzhnaya et al., } \\
\text { 2006; Kalyuzhnaya et } \\
\text { al., 2012) }\end{array}$ \\
\hline Rhodocyclales & $\begin{array}{l}\text { Rhodocyclaceae: mainly } \\
\text { C16:0, C16:1cis-9, C18:1; } \\
\text { only traces of C14:0 and } \\
\text { C18:0 }\end{array}$ & $\begin{array}{l}\text { (Reinhold-Hurek et al., } \\
\text { 1993; Anders et al., } \\
\text { 1995) }\end{array}$ \\
\hline
\end{tabular}




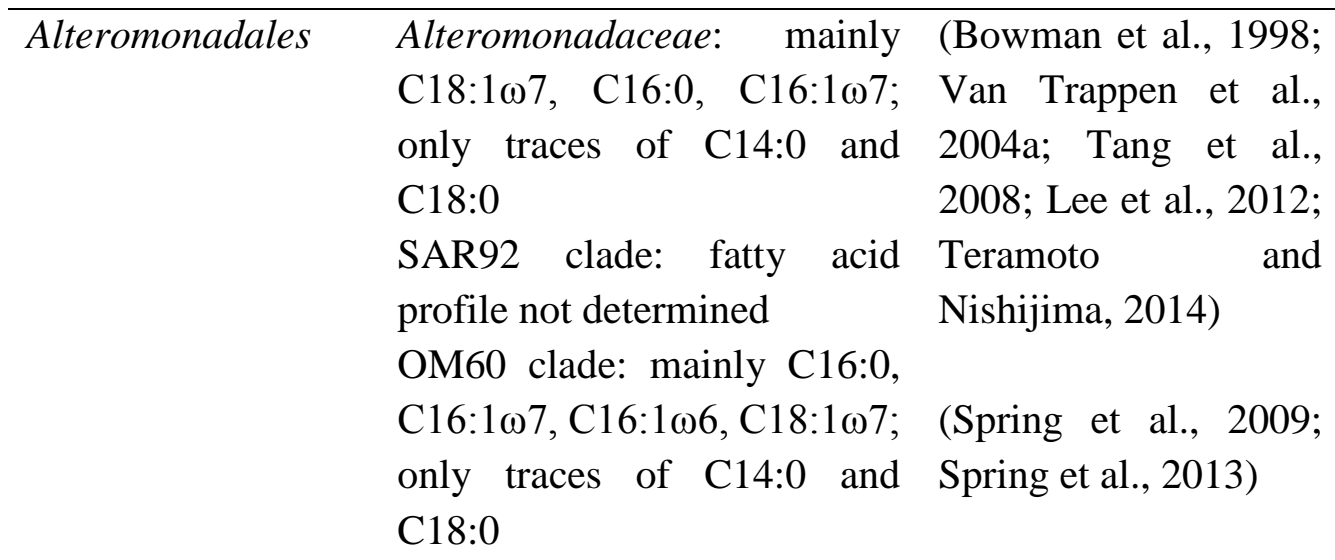

Oceanospirillales Halomonadaceae: mainly (Sánchez-Porro et al., C16:0, C18:1 $\omega 7$; minor 2009; Long et al., amounts of $\mathrm{C} 14: 0, \mathrm{C} 16: 1 \omega 7 ; 2013)$ traces of $\mathrm{C} 18: 0$

Thiotrichales Piscirickettsiaceae: mainly (Doronina et al., 2003;

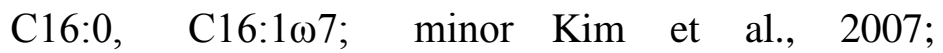
amounts of C14:0; traces of Antony et al., 2012) C18:0

Thiotrichaceae: mainly (Aruga et al., 2002)

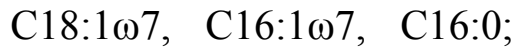
minor amounts of C14:0, C18:0

Puniceicoccales Coraliomargarita: mainly (Yoon et al., 2007b)

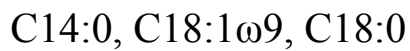

Verrucomicrobiales Verrucomicrobiaceae: mainly (Yoon et al., 2008) C16:0, some also C14:0 and C16:1 107

Chlorophyta

Mamiellales: mainly C16:0, (Martínez-Fernández

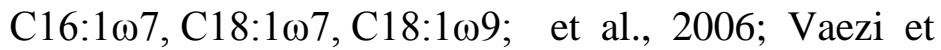
only traces of C14:0 and al., 2013) C18:0

Stramenopiles (diatoms)

Thalassiosira: mainly C14:0, (Viso and Marty,

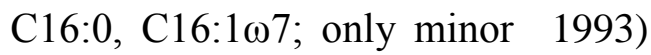
amounts of C18:0

Chaetoceros: mainly C14:0, (Viso and Marty, 1993;

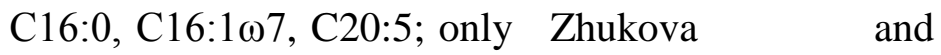
minor amounts of C18:0 Aizdaicher, 1995) 


\begin{tabular}{|c|c|c|}
\hline Haptophyta & $\begin{array}{l}\text { Phaeocystis: mainly } \mathrm{C} 14: 0 \text {, } \\
\mathrm{C} 16: 0, \mathrm{C} 18: 1 \omega 9 ; \\
\text { amounts of } \mathrm{C} 16: 1 \omega 7, \mathrm{C} 18: 0 \\
\text { and } \mathrm{C} 20: 5 \text { PUFA }\end{array}$ & $\begin{array}{l}\text { (Al-Hasan et al., 1990; } \\
\text { Nichols et al., 1991; } \\
\text { Hamm and Rousseau, } \\
\text { 2003) }\end{array}$ \\
\hline Cryptophyta & 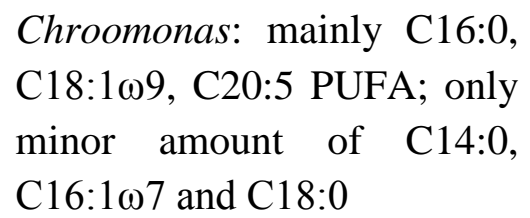 & $\begin{array}{l}\text { (Viso and Marty, 1993; } \\
\text { Zhukova and } \\
\text { Aizdaicher, 1995) }\end{array}$ \\
\hline
\end{tabular}

Al-Hasan, R. H., Ali, A. M., and Radwan, S. S.: Lipids, and their constituent fatty acids, of Phaeocystis sp. from the Arabian Gulf, Mar Biol, 105, 9-14, 10.1007/bf01344265, 1990.

Anders, H.-J., Kaetzke, A., Kämpfer, P., Ludwig, W., and Fuchs, G.: Taxonomic position of aromatic-degrading denitrifying Pseudomonad strains K 172 and KB 740 and their description as new members of the genera Thauera, as Thauera aromatica sp. nov., and Azoarcus, as Azoarcus evansii sp. nov., respectively, members of the Beta subclass of the Proteobacteria, Int J Syst Bacteriol, 45, 327-333, 10.1099/00207713-45-2-327, 1995.

Antony, C. P., Doronina, N. V., Boden, R., Trotsenko, Y. A., Shouche, Y. S., and Murrell, J. C.: Methylophaga lonarensis sp. nov., a moderately haloalkaliphilic methylotroph isolated from the soda lake sediments of a meteorite impact crater, Int J Syst Evol Microbiol, 62, 1613-1618, 10.1099/ijs.0.035089-0, 2012.

Aruga, S., Kamagata, Y., Kohno, T., Hanada, S., Nakamura, K., and Kanagawa, T.: Characterization of filamentous Eikelboom type $021 \mathrm{~N}$ bacteria and description of Thiothrix disciformis sp. nov. and Thiothrix flexilis sp. nov, Int J Syst Evol Microbiol, 52, 1309-1316, 10.1099/ijs.0.02177-0, 2002.

Bowman, J. P., McCammon, S. A., Brown, J. L., and McMeekin, T. A.: Glaciecola punicea gen. nov., sp. nov. and Glaciecola pallidula gen. nov., sp. nov.: psychrophilic bacteria from Antarctic sea-ice habitats, Int J Syst Bacteriol, 48, 1213-1222, 10.1099/00207713-48-4-1213, 1998.

Bowman, J. P., Nichols, C. M., and Gibson, J. A. E.: Algoriphagus ratkowskyi gen. nov., sp. nov., Brumimicrobium glaciale gen. nov., sp. nov., Cryomorpha ignava gen. nov., sp. nov. and Crocinitomix catalasitica gen. nov., sp. nov., novel flavobacteria isolated from various polar habitats, Int J Syst Evol Microbiol, 53, 1343-1355, 10.1099/ijs.0.02553-0, 2003.

Doronina, N., Darmaeva, T., and Trotsenko, Y.: Methylophaga natronica sp. nov., a new alkaliphilic and moderately halophilic, restricted-facultatively methylotrophic bacterium from soda lake of the Southern Transbaikal Region, Syst Appl Microbiol, 26, 382-389, 10.1078/072320203322497419, 2003. 
Evtushenko, L., and Takeuchi, M.: The Family Microbacteriaceae, in: The Prokaryotes, edited by: Dworkin, M., Falkow, S., Rosenberg, E., Schleifer, K.-H., and Stackebrandt, E., Springer New York, 1020-1098, 2006.

Gallego, V., García, M. T., and Ventosa, A.: Pedobacter aquatilis sp. nov., isolated from drinking water, and emended description of the genus Pedobacter, Int J Syst Evol Microbiol, 56, 18531858, 10.1099/ijs.0.64176-0, 2006.

Hamm, C. E., and Rousseau, V.: Composition, assimilation and degradation of Phaeocystis globosa-derived fatty acids in the North Sea, J Sea Res, 50, 271-283, 10.1016/s13851101(03)00044-3, 2003.

Heindl, H., Wiese, J., and Imhoff, J. F.: Tenacibaculum adriaticum sp. nov., from a bryozoan in the Adriatic Sea, Int J Syst Evol Microbiol, 58, 542-547, 10.1099/ijs.0.65383-0, 2008.

Jung, Y.-T., Kim, B.-H., Oh, T.-K., and Yoon, J.-H.: Pseudoruegeria lutimaris sp. nov., isolated from a tidal flat sediment, and emended description of the genus Pseudoruegeria, Int J Syst Evol Microbiol, 60, 1177-1181, 10.1099/ijs.0.015073-0, 2010.

Kalyuzhnaya, M. G., Bowerman, S., Lara, J. C., Lidstrom, M. E., and Chistoserdova, L.: Methylotenera mobilis gen. nov., sp. nov., an obligately methylamine-utilizing bacterium within the family Methylophilaceae, Int J Syst Evol Microbiol, 56, 2819-2823, 10.1099/ijs.0.64191-0, 2006.

Kalyuzhnaya, M. G., Beck, D. A. C., Vorobev, A., Smalley, N., Kunkel, D. D., Lidstrom, M. E., and Chistoserdova, L.: Novel methylotrophic isolates from lake sediment, description of Methylotenera versatilis sp. nov. and emended description of the genus Methylotenera, Int J Syst Evol Microbiol, 62, 106-111, 10.1099/ijs.0.029165-0, 2012.

Kerger, B. D., Mancuso, C. A., Nichols, P. D., White, D. C., Langworthy, T., Sittig, M., Schlesner, H., and Hirsch, P.: The budding bacteria, Pirellula and Planctomyces, with atypical 16S rRNA and absence of peptidoglycan, show eubacterial phospholipids and uniquely high proportions of long chain beta-hydroxy fatty acids in the lipopolysaccharide lipid A, Arch Microbiol, 149, 255-260, 10.1007/bf00422014, 1988.

Khan, S. T., Nakagawa, Y., and Harayama, S.: Sediminicola luteus gen. nov., sp. nov., a novel member of the family Flavobacteriaceae, Int J Syst Evol Microbiol, 56, 841-845, 10.1099/ijs.0.64047-0, 2006.

Kim, H. G., Doronina, N. V., Trotsenko, Y. A., and Kim, S. W.: Methylophaga aminisulfidivorans sp. nov., a restricted facultatively methylotrophic marine bacterium, Int J Syst Evol Microbiol, 57, 2096-2101, 10.1099/ijs.0.65139-0, 2007. 
Lee, O. O., Lai, P. Y., Wu, H.-X., Zhou, X.-j., Miao, L., Wang, H., and Qian, P.-Y.: Marinobacter xestospongiae sp. nov., isolated from the marine sponge Xestospongia testudinaria collected from the Red Sea, Int J Syst Evol Microbiol, 62, 1980-1985, 10.1099/ijs.0.028811-0, 2012. Long, M.-R., Zhang, D.-F., Yang, X.-Y., Zhang, X.-M., Zhang, Y.-G., Zhang, Y.-M., Zhu, H., and Li, W.-J.: Halomonas nanhaiensis sp. nov., a halophilic bacterium isolated from a sediment sample from the South China Sea, Antonie van Leeuwenhoek, 103, 997-1005, 10.1007/s10482013-9879-3, 2013.

sequence data, Nucleic Acids Res, 32, 1363-1371, 10.1093/nar/gkh293, 2004.

Martínez-Fernández, E., Acosta-Salmón, H., and Southgate, P. C.: The nutritional value of seven species of tropical microalgae for black-lip pearl oyster (Pinctada margaritifera, L.) larvae, Aquaculture, 257, 491-503, 10.1016/j.aquaculture.2006.03.022, 2006.

Nichols, P. D., Skerratt, J. H., Davidson, A., Burton, H., and McMeekin, T. A.: Lipids of cultured Phaeocystis pouchetii: Signatures for food-web, biogeochemical and environmental studies in Antarctica and the Southern ocean, Phytochemistry, 30, 3209-3214, 10.1016/00319422(91)83177-M, 1991.

O'Sullivan, L. A., Rinna, J., Humphreys, G., Weightman, A. J., and Fry, J. C.: Fluviicola taffensis gen. nov., sp. nov., a novel freshwater bacterium of the family Cryomorphaceae in the phylum 'Bacteroidetes', Int J Syst Evol Microbiol, 55, 2189-2194, 10.1099/ijs.0.63736-0, 2005.

Park, S., and Yoon, J. H.: Octadecabacter jejudonensis sp nov., isolated from the junction between the ocean and a freshwater spring and emended description of the genus Octadecabacter, Int J Syst Evol Microbiol, 64, 719-724, 10.1099/ijs.0.057513-0, 2014.

Reinhold-Hurek, B., Hurek, T., Gillis, M., Hoste, B., Vancanneyt, M., Kersters, K., and De Ley, J.: Azoarcus gen. nov., nitrogen-fixing Proteobacteria associated with roots of Kallar grass (Leptochloa fusca (L.) Kunth), and description of two species, Azoarcus indigens sp. nov. and Azoarcus communis sp. nov, Int J Syst Bacteriol, 43, 574-584, 10.1099/00207713-43-3-574, 1993.

Sánchez-Porro, C., de la Haba, R. R., Soto-Ramírez, N., Márquez, M. C., Montalvo-Rodríguez, R., and Ventosa, A.: Description of Kushneria aurantia gen. nov., sp. nov., a novel member of the family Halomonadaceae, and a proposal for reclassification of Halomonas marisflavi as Kushneria marisflavi comb. nov., of Halomonas indalinina as Kushneria indalinina comb. nov. and of Halomonas avicenniae as Kushneria avicenniae comb. nov, Int J Syst Evol Microbiol, 59, 397-405, 10.1099/ijs.0.001461-0, 2009.

Schlesner, H., Rensmann, C., Tindall, B. J., Gade, D., Rabus, R., Pfeiffer, S., and Hirsch, P.: Taxonomic heterogeneity within the Planctomycetales as derived by DNA-DNA hybridization, description of Rhodopirellula baltica gen. nov., sp. nov., transfer of Pirellula marina to the genus 
Blastopirellula gen. nov. as Blastopirellula marina comb. nov. and emended description of the genus Pirellula, Int J Syst Evol Microbiol, 54, 1567-1580, 10.1099/ijs.0.63113-0, 2004.

Tang, S.-K., Wang, Y., Cai, M., Lou, K., Mao, P.-H., Jin, X., Jiang, C.-L., Xu, L.-H., and Li, W.J.: Microbulbifer halophilus sp. nov., a moderately halophilic bacterium from north-west China, Int J Syst Evol Microbiol, 58, 2036-2040, 10.1099/ijs.0.65519-0, 2008.

Teramoto, M., and Nishijima, M.: Agaribacter marinus gen. nov., sp. nov., an agar-degrading bacterium from surface seawater, Int $J$ Syst Evol Microbiol, 64, 2416-2423, 10.1099/ijs.0.061150-0, 2014.

Vaezi, R., Napier, J. A., and Sayanova, O.: Identification and functional characterization of genes encoding omega-3 polyunsaturated fatty acid biosynthetic activities from unicellular microalgae, Marine Drugs, 11, 5116-5129, 10.3390/md11125116, 2013.

Van Trappen, S., Tan, T.-L., Yang, J., Mergaert, J., and Swings, J.: Alteromonas stellipolaris sp. nov., a novel, budding, prosthecate bacterium from Antarctic seas, and emended description of the genus Alteromonas, Int J Syst Evol Microbiol, 54, 1157-1163, 10.1099/ijs.0.02862-0, 2004a. Van Trappen, S., Vandecandelaere, I., Mergaert, J., and Swings, J.: Flavobacterium degerlachei sp. nov., Flavobacterium frigoris sp. nov. and Flavobacterium micromati sp. nov., novel psychrophilic bacteria isolated from microbial mats in Antarctic lakes, Int J Syst Evol Microbiol, 54, 85-92, 10.1099/ijs.0.02857-0, 2004b.

Venkata Ramana, V., Anil Kumar, P., Srinivas, T. N. R., Sasikala, C., and Ramana, C. V.: Rhodobacter aestuarii sp. nov., a phototrophic alphaproteobacterium isolated from an estuarine environment, Int J Syst Evol Microbiol, 59, 1133-1136, 10.1099/ijs.0.004507-0, 2009.

Viso, A.-C., and Marty, J.-C.: Fatty acids from 28 marine microalgae, Phytochemistry, 34, 15211533, 10.1016/S0031-9422(00)90839-2, 1993.

Yoon, J.-H., Lee, S.-Y., Kang, S.-J., Lee, C.-H., and Oh, T.-K.: Pseudoruegeria aquimaris gen. nov., sp. nov., isolated from seawater of the East Sea in Korea, Int J Syst Evol Microbiol, 57, 542-547, 10.1099/ijs.0.64594-0, 2007a.

Yoon, J., Yasumoto-Hirose, M., Katsuta, A., Sekiguchi, H., Matsuda, S., Kasai, H., and Yokota, A.: Coraliomargarita akajimensis gen. nov., sp. nov., a novel member of the phylum 'Verrucomicrobia' isolated from seawater in Japan, Int J Syst Evol Microbiol, 57, 959-963, 10.1099/ijs.0.64755-0, 2007b.

Yoon, J., Matsuo, Y., Katsuta, A., Jang, J.-H., Matsuda, S., Adachi, K., Kasai, H., and Yokota, A.: Haloferula rosea gen. nov., sp. nov., Haloferula harenae sp. nov., Haloferula phyci sp. nov., Haloferula helveola sp. nov. and Haloferula sargassicola sp. nov., five marine representatives of the family Verrucomicrobiaceae within the phylum 'Verrucomicrobia', Int J Syst Evol Microbiol, 58, 2491-2500, 10.1099/ijs.0.2008/000711-0, 2008. 
Zhukova, N. V., and Aizdaicher, N. A.: Fatty acid composition of 15 species of marine microalgae, Phytochemistry, 39, 351-356, 10.1016/0031-9422(94)00913-E, 1995. 